\title{
Preface: Recent progress in environmental hydrogeochemistry
}

\author{
JING ZHANG* and MINORU KUSAKABE
}

Graduate School of Science and Engineering, University of Toyama, Gofuku 3190, Toyama 930-8555, Japan

Geochemistry today is an interdisciplinary science covering a wide range of research areas. Since the "Geochemische Verteilungsgesetze der Elemente" (geochemical laws of the distribution of the elements) were posed in 1922 by Victor Moritz Goldschmidt (a father of modern geochemistry, together with Володимир Іванович Вернадський (English: Vladimir Ivanovich Vernadsky)), almost a century has passed, but the foundation of geochemistry remains the same, to use the tools and principles of chemistry to explain the mechanisms behind major natural geological systems. Today, hydrobiogeochemistry and aqueous geochemistry study the roles and fluxes of various elements through atmosphericterrestrial-aquatic interactions in the hydrosphere.

Given the pressing need to better understand and protect the earth's environments in the 21 st century, environmental geochemistry is a discipline with urgent issues to address, since it is through present and past records of biogeochemical processes that understanding of globally changing patterns can be accurately obtained, on long time scales such as weathering of mountain ranges, medium time scales of climate, and short times scales such as tsunamis or landslides.

Our global environment is changing rapidly and broadly in scales such as "global warming" which we have never experienced in the past. In September 2013, the Fifth Assessment Report (AR5)_Climate Change 2013: The Physical Science Basis was issued in Stockholm. Whatever the criteria and metrics, there is no doubt nowadays that global warming and associated effects are occurring faster and more broadly than ever, resulting in extreme and irreversible impacts to the earth environment that extend to regional and local scales. In Japan, everyone notices the summer maximum air temperature is updated: the Japan Meteorological Agency continues redefining new words for extremely hot days, "Manatsu" for $30^{\circ} \mathrm{C}$, "Mo-sho" for $35^{\circ} \mathrm{C}$ in 2007 , and maybe "Kokusho" for $40^{\circ} \mathrm{C}$ in the next years.

Like many other countries in eastern Asia, Japan benefits greatly from the water lifeblood of the monsoon, but

*Corresponding author (e-mail: jzhang@sci.u-toyama.ac.jp)

Copyright (c) 2013 by The Geochemical Society of Japan. environmental issues related to the water system often occur. Recently, continuous storms with heavy rain and inundation caused serious damages to our community. Furthermore, the observed lessening of snow cover exacerbates the ongoing reduction of ground water, and it will get worse. Dust and Kosa from central Asia and China are adversely affecting forest ecosystems in Japan and changing the nutrient flow leading to large impacts on the coastal ecosystem via a changed water chemistry.

With the aim to better understand the environmental protection and maintenance of the biosphere via water cycles, this special issue casts a broad net to current studies of environmental geochemistry in the hydrosphere, and to provision of a broad forum to strengthen future cooperation and the interdisciplinary nature of hydrogeochemical research. The issue contends ten papers $(8$ articles and two notes) covering major ion geochemistry, stable isotopic and trace element research related to the terrestrial hydro-system, air pollution, speciation measurements and analytical developments.

Iwatake et al. (2013) using chemical and isotopic (D, O) compositions of 56 water samples from the Sho River fan, Toyama, northern part of central Japan, discussed the ground water geochemistry, water quality, origins and water flow. The geothermal gradient is about twice as other areas in Japan and it might mean that high temperature geothermal sources lay under the study region. On the basis of water flow pattern and examination of precipitation materials in heat exchangers, the shallow groundwaters in this region can be very useful for heat usage by open-type heat pump system.

The chemical and stable $(\mathrm{D}, \mathrm{O})$ isotopic compositions of 20 groundwaters and river waters in the Hakusan area, the home of the well known "Hakusan" sake, were analyzed to investigate their origins and water flow (Tomiyama et al., 2013). The results show that the groundwater originates from river water between $200 \mathrm{~m}$ and 600 $m$ altitude. Numerical simulation of groundwater flow also supports this view that the groundwater for "Hakusan" flows from a flank of mountain, 2 to $3 \mathrm{~km}$ far from the sake brewery. These results indicate that simultaneous analyses of numerical and geochemical techniques can estimate the origin and water movement of groundwater, in this case to promote sake production. 
A detailed geochemical study of surface waters in the Tateyama caldera where large-scale landslides often occur was undertaken in order to clarify their characteristics and relationship to the landslides (Sato et al., 2013). The chemical composition and $\delta^{34} \mathrm{~S}$ values of $\mathrm{SO}_{4}{ }^{2-}$ of the stream waters suggest that dissolution of rockforming minerals such as plagioclase by sulfuric acid produced by oxidation of pyrite that formed during alteration of volcanic rocks is occurring. Intense rock weathering at the head areas of sulfate-rich streams is likely to have caused the 1964 large-scale landslide there. Positive correlation between $\mathrm{SO}_{4}{ }^{2-}$ concentration in the streams and a ratio of landslide area to the catchment area indicates that hydro-geochemical information at landslide areas has a potential of identifying the area of future landslide.

With the aim of understanding the origin of acid rain and its potential impacts on $\mathrm{CO}_{2}$ uptake by carbonate weathering in rural area of Southwest China, Ding et al. (2013) analyzed rainwater collected from Huanjiang, China. Chemical content and $\delta^{34} \mathrm{~S}-\mathrm{SO}_{4}{ }^{2-}$ values in rain water show the chemicals were mainly derived from sea salt, the Earth's crust, and anthropogenic sources respectively. The authors estimated that anthropogenic sources of sulfate in the atmosphere (mainly from coal combustion) were responsible for a $9.6 \%$ decrease in $\mathrm{CO}_{2}$ consumption rates in the study area. This indicates that involvement of anthropogenic derived sulfate can largely decrease the carbon uptake rate of carbonate weathering in rural karst regions.

Wang et al. (2013) reported that the water-particle interaction processes evidenced using sequential chemical extractions for suspended particles. In the studied alkaline lakes, lower concentrations of dissolved rare earth elements were observed than most of previously reported terrestrial surface waters of the world due to their high $\mathrm{pH}$. For the first time, a liner relationship between $\mathrm{pH}$ and the REE concentrations shows in a wide $\mathrm{pH}$ range and exhibits the tendency as a "three stage model", indicates that the geochemical behavior of dissolved REEs are mainly controlled by $\mathrm{pH}$ in surface waters. Lanthanum and Cerium anomalies were discussed, and the positive correlation of the Ce anomaly with the redox sensitive species $\mathrm{Mn}$ indicates that the redox reaction is the main process for controlling the Ce anomaly in the studied lakes.

Sequential chemical extraction of arsenic and related elements in the Holocene sediments from Sonargaon, a heavily As-contaminated groundwater area in Bangladesh, was studied by Masuda et al. (2013). A significant amount of As, together with $\mathrm{Si}, \mathrm{Al}, \mathrm{Mg}$, and Fe, was extracted by oxidation-decomposition of the silicates during a sequential chemical extraction process, indicating that chemical weathering of As-bearing silicate(s), which mostly oc- curs under oxic aqueous conditions, results in As dissolution in nature. As was fixed mainly in chlorite in the As-contaminated Holocene groundwater aquifer of Sonargaon, Silicate minerals, especially $\mathrm{Mg}$ - and Febearing minerals, were partly decomposed by oxidation to release a considerable fraction of As in the extracts, suggesting that oxidation-decomposition of As-bearing chlorite occurred in the aquifer. This result agrees with previous results that indicated chlorite was the host phase of As and that oxidation-decomposition of this mineral was the primary cause of As-contaminated groundwater (Masuda et al., 2012).

Horikawa et al. (2013), analyzed Ca, Mg, Mn, Sr, Ba, and $\mathrm{Pb}$ concentrations in tree-rings of a Tateyama cedar (Cryptomeria japonica) at Bijodaira, covering a record from 1915 to 1993 , to understand when soil acidification began, the extent of soil acidification, and its influence on forest soil environments. The radial distributions of each element in the Tateyama cedar were classified into four groups: (I) increasing concentrations toward the outermost ring $\left(\mathrm{Ca}^{2+}\right.$ and $\left.\mathrm{Mn}^{2+}\right)$; (II) sharp decrease across the heartwood/sapwood boundary $\left(\mathrm{Mg}^{2+}\right)$; (III) higher values in the late 1950 s and around 1990 superimposed on the slightly increasing trend from the 1920s $\left(\mathrm{Sr}^{2+}\right.$ and $\left.\mathrm{Ba}^{2+}\right)$; and (VI) higher values around the late 1960s to early 1980s $\left(\mathrm{Pb}^{2+}\right)$.

Chemical substances over the northern Japan Alps were measured by Toyama et al. (2013) at six sites. Vertical profile variations of chemical components in the snow layers were obtained at each sampling location. The nss- $\mathrm{SO}_{4}{ }^{2-}$ concentrations in snow were shown to reduce exponentially with increasing distance from the coast to the Japan Alps, although it decreased sharply at three sites located monsoon-leeward of the Japan Alps. This suggests that the anthropogenic components transported from the Asian continent with the monsoon were gradually removed from air and deposited in the snow cover as the air masses passed over the Northern Japan Alps.

The newest analytical developments are required to shed light on the current complicated environment geochemical issues. Two analytical processing reports are included in this special issue.

High-precision measurements of water isotopes using laser absorption spectroscopy were reported by Maruyama et al. (2013). Analysis using an off-axis integratedcavity output spectroscopy (OA-ICOS) was carefully checked for long-term stabilities, dependence on the injected water volume, inter-sample memory effects, and influence of salinity, with an aim to investigate whether it can be an alternative to conventional isotope ratio mass spectrometry (IRMS). The results suggest that the OAICOS method can be an alternative to IRMS for $\delta \mathrm{D}$ and $\delta^{18} \mathrm{O}$ analysis of natural water.

The design and operation of an in situ contamination- 
free sampler of submarine spring water for $\mathrm{CFCs}_{\text {s }}$ and $\mathrm{SF}_{6}$ analysis are described by Asai et al. (2013). Samples from a submarine freshwater spring, discharging along the southwest coast of Rishiri Island, Japan, had CFC and $\mathrm{SF}_{6}$ ages of 1960-1970, which is consistent with previously reported ${ }^{3} \mathrm{H}$ ages. This suggests suitability of the sampler for sampling submarine springs without atmospheric and seawater contamination. Moreover, the device is suitable for the collection of water samples for the assessment of geochemical tracers, such as major dissolved gases, isotopes, and inorganic solutes.

We are grateful to all the authors for their contributions and all the reviewers for their devoted help and advice for improving the manuscripts. We further thank Professors Yuji Sano and Hisayoshi Yurimoto, former and current Chief Editors of Geochemical Journal. Finally, we acknowledge the contributions and deep insight of late Professor Hiroshi Satake, who developed and improved many elegant, simple and inexpensive analytical techniques for various stable isotopic measurements, as well as practical methodologies to solve real world problems and the evermore pressing environmental issues in the surface water system.

\section{REFERENCES}

Asai, K., Zhang, J., Asai, K., Mogi, K., Fantong, W. Y. and Mandal, A. K. (2013) Development of an in situ sampler of submarine springs for the analysis of $\mathrm{CFCs}$ and $\mathrm{SF}_{6}$. Geochem. J. 47, this issue, 693-696.

Ding, H., Lang, Y.-C., Liu, C.-Q. and Liu, T.-Z. (2013) Chemical characteristics and $\delta^{34} \mathrm{~S}-\mathrm{SO}_{4}{ }^{2-}$ of acid rain: Anthropogenic sulfate deposition and its impacts on $\mathrm{CO}_{2}$ consumption in the rural karst area of southwest China. Geochem.J. 47, this issue, 625-638.

Horikawa, K., Takeda, M., Kawasaki, K. and Zhang, J. (2013)
Historical changes in soil acidification inferred from the dendrochemistry of a Tateyama cedar at Bijodaira, Mt. Tateyama, Japan. Geochem. J. 47, this issue, 663-673.

Iwatake, K., Mizoguchi, T., Tomiyama, S., Zhang, J., Satake, H. and Ueda, A. (2013) Geochemical study of groundwater in the Sho river fan, Toyama Prefecture for heat usage by geothermal heat pump. Geochem. J. 47, this issue, 577-590.

Maruyama, S., Tanaka, Y., Hirayama, S., Kusakabe, M., Zhang, J. and Nakano, T. (2013) High-precision measurements of water isotopes using laser absorption spectroscopy. Geochem. J. 47, this issue, 675-682.

Masuda, H., Shinoda, K., Okudaira, T., Takahashi, Y. and Noguchi, N. (2012) Chlorite-source of arsenic groundwater pollution in the Holocene aquifer of Bangladesh. Geochem. J. 46, 381-391.

Masuda, H., Okabayashi, K., Maeda, S., Seddique, A. A., Mitamura, M. and Shinoda, K. (2013) Sequential chemical extraction of arsenic and related elements from the Holocene sediments of Sonargaon, Bangladesh, in relation to formation of arsenic-contaminated groundwater. Geochem. J. 47, this issue, 651-661.

Sato, Y., Kometani, M., Satake, H., Nozaki, T. and Kusakabe, M. (2013) Calcium-sulfate rich water in landslide area of Tateyama Caldera, northern central Japan. Geochem. J. 47, this issue, 609-623.

Tomiyama, S., Hashiguchi, T., Ueda, A., Kitai, A., Izu, H. and Sudo, S. (2013) Geochemical, stable isotope, and numerical modeling studies of sake and groundwater for identification of the location of sake production: A case study from Hakusan City, Japan. Geochem. J. 47, this issue, 591-608.

Toyama, K., Zhang, J. and Satake, H. (2013) Long-range transportation and deposition of chemical substances over the Northern Japan Alps mountainous area. Geochem. J. 47, this issue, 683-692.

Wang, Z.-L., Liu, C.-Q. and Zhu, Z.-Z. (2013) Rare earth element geochemistry of waters and suspended particles in alkaline lakes using extraction and sequential chemical methods. Geochem. J. 47, this issue, 639-649. 